\title{
Development of elements of an information and resource digital platform for intelligent management of agricultural and land use systems in terms of transferring advanced knowledge and experience in organizing highly productive agricultural enterprises of a new technological paradigm
}

\section{I.A. Ganieva, and S.V. Koteev*}

All-Russian Institute of Agrarian Problems and Informatics named after A. A. Nikonov - Branch of the Federal Research Center for Agricultural Economics and Social Development of Rural Territories - VNIIESH, 107078 Moscow, Russian Federation

\begin{abstract}
The article is devoted to theoretical and practical issues of creating a new industry information resource "Open agricultural University" - a digital platform for additional professional education to increase labor productivity in agriculture. The relevance of creating such a platform is justified, and a brief description of the current directions of technological development of the project is given, including the integration of end - to-end digital technologies-artificial intelligence, virtual and augmented reality, for the development and provision of new services through the educational resource.
\end{abstract}

\section{Introduction}

The accelerated transition to a highly productive agricultural economy of a new technological paradigm, the digital transformation of the agro-industrial complex require new advanced knowledge in specialized areas. Additional professional education is a real opportunity to increase labor productivity in various industries and make a leap forward in the modern Russian economy in the near future. The speed of transformation is quite likely to accelerate under the influence of significant restrictions in traditional processes that the global pandemic of 2020 has set. Even now, an impressive proportion of additional professional education programs are implemented remotely through online platforms, while in the field of agricultural education there are no specialized educational platforms, they are replaced by electronic educational resources of agricultural educational institutions, which contain mainly standard educational courses formed according to the requirements of state educational standards and do not represent practical value for agribusiness [26, p. 22].

\footnotetext{
*Corresponding author: viapi@mail.ru
} 
The research substantiates the relevance of additional professional education for increasing labor productivity in agriculture, as well as online education and on its basis the system transformation of traditional educational systems and processes with the introduction of digital technologies. The article describes the digital educational platform "Open Agrarian University" developed and undergoing implementation as a result of partnership between a scientific organization, an industrial partner and agricultural universities in Russia. Special attention is paid to the problems of online education market research in Russia. A brief description of the current directions of technological development of the project, including the integration of end-to-end digital technologies artificial intelligence, virtual and augmented reality, for the development and provision of new services through the educational resource [26, p. 24]. It is noted that the "Open Agrarian University" offers a number of advantages to both users and providers of educational content. Typical problems identified during the implementation of the platform are formulated: the need to develop high-quality content taking into account the needs of agribusiness, insufficient coverage of rural areas with mobile communications and Internet access. It is noted that the advantage of the digital platform for agriculture is the interest of the industrial partner of this project, which has a deep and broad presence in the market of products for agriculture, as well as the possibility of implementing the project in the model of public-private partnership - with state educational institutions, state corporations, industry unions.

\section{Materials and methods}

In the study of modern conditions, prerequisites, and limitations of creating a digital educational platform for the implementation of distance education services in the agricultural sector [26, p.22], empirical methods were used, including the study of sources of officially published information (scientific articles, regulations), analysis of the information obtained, and the survey method. Theoretical research methods included analysis, classification, and analogy [26, p. 22].

The authors noted the advantages of the digital platform for agriculture, which consist in the interest of the industrial partner of this project, which has a deep and broad presence in the market of products for agriculture, as well as the possibility of implementing the project in the model of public-private partnership - with state educational institutions, state corporations, industry unions.

The goal was achieved-to create a single digital educational platform that provides a high technological level for the implementation of a wide range of distance education services in the field of agriculture, intended for specialists working in the agro-industrial complex of Russia and the CIS.

One of the most important tasks to stimulate the digital transformation of the agroindustrial complex is training and advanced training of personnel. It is necessary to develop and implement new educational programs, disciplines and courses on the digital agricultural economy, develop appropriate textbooks and manuals, video and audio materials, organize thematic seminars and webinars, record thematic podcasts, etc. As publications in this field show, first of all, it is necessary to train specialists in the field of the Internet of things, control of unmanned aerial vehicles (drones), precision agriculture, robotization of production, etc. Agricultural universities of the Ministry of Agriculture of Russia can and should become centers of training and advanced training in the field of digital agriculture.

The results of research on the online education market in Russia [11, p. 13-19] demonstrate the following imperatives that are important to consider when creating an industry-specific agricultural educational online resource [26, p. 22]: about half $(42 \%)$ of 
all educational content is created for adults, including $26 \%$ created for specialists in specific industries; the most popular duration of distance learning is a period of 1-3 months - this is $40 \%$ of all courses offered, courses lasting 1 month occupy a share of $18 \%$, long courses from six months to a year occupy a $14 \%$ share of the online educational market. Most often, clients of educational platforms choose a course with a focus on the quality of the offered content (quality of video lectures, interactive elements, stylish additional materials and the presence of useful links) [26, p. 22] - 54\% of influence on the choice, the second choice factor is the ability to get personal expert advice through the platform - this is significant for $53 \%$ of students, followed by technology, methodology and training program, the presence of the best teachers and experts [26, p. 22].

We also note, based on expert opinions and opinion polls of agribusiness, that in most cases online educational services are independently used by managers and chief specialists of agricultural enterprises [26, p. 22]. The new portrait of the head of the Russian agricultural business is a modern user of mobile devices, looking for answers to constantly emerging questions and seeking quick and qualified answers from the best experts in the industry.

Based on the study "Online education market research in Russia" [11], we can conclude that the business model of creating a digital educational platform is quite common $-77 \%$ of online education models are concentrated in the category of online school, course, university. Another clear pattern is that content is created for the adult population (42\%), as well as for specialists in any industry (26\%). In this regard, there is a demand for online resources that have certain industry specifics, including agricultural ones.

However, educational resources functioning online cannot meet the needs of agricultural businesses in obtaining high-quality knowledge.

A systematic study of the needs for additional education services by remote methods of a wide range of clients of a large company producing fertilizers for soil and plants, including agricultural producers, manufacturers of agricultural machinery, plant protection products, service providers for agricultural enterprises, specialists and teachers of agricultural universities allowed to formulate major directions for the most frequent business requests and individual issues that require professional expert advice.

According to the results of a separate survey in the form of a questionnaire and an oral survey conducted among more than 300 managers and chief specialists of agricultural enterprises in 2019-2020, the main requests of agricultural business for information were identified, including the most common requests to existing information systems and Internet resources (figure 1). 


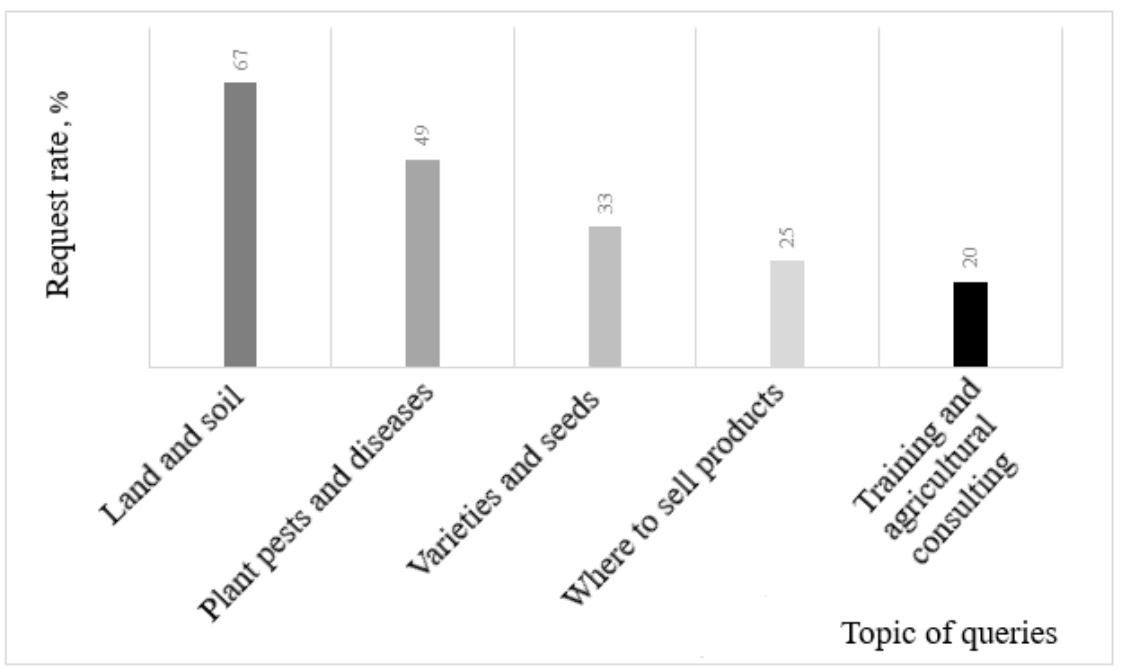

Fig. 1. The main requests of agribusiness for relevant information search [26, p. 22-24].

The author of this work conducted numerous surveys of representatives of agricultural business (level - first managers, chief specialists), which allowed us to determine the list of agribusiness problems related to obtaining additional education of their specialists, with the need to obtain additional competencies and skills.

The problems are outlined below:

- in Russia, there is no specialized online educational platform for owners and managers of agribusiness, aimed at spreading relevant applied knowledge in agriculture and agribusiness;

- the most acceptable training format is a mixed format: $80 \%$ online training, $20 \%$ live meetings of experts and clients in the regions;

- there is no opportunity to get knowledge from key experts in agriculture and agribusiness;

- there is a need for knowledge that provides comprehensive training in various aspects of agribusiness - from methods of regulating the phytosanitary state of the soil to proper preparation for inspections by state regulatory authorities;

- practical and up-to-date knowledge is required, which allows to get only the necessary knowledge;

- there is a need for long complex and short-term modular programs; such formats of educational courses allow to get a complete education in agribusiness during the annual course, and to delve into the most relevant point problems by studying short modules;

- continuous access to knowledge is required, 24/7, on all available data transfer devices (computer, tablet, smartphone);

- all educational materials, case studies, materials of practical classes and seminars should be available online, which allows to plan own time for training and provides effective time management during the "hot" agricultural seasons;

- often a personal curriculum is required for each client, which can be achieved through a modular structure of the educational process, when the client can choose only those courses and sections of knowledge that they are interested in, without spending time and money on general or irrelevant courses;

- everyone is interested in independent expertise and experience of colleagues.

Digital educational platforms for distance education have become increasingly widespread in recent years. It is logical to assume that the global coronavirus pandemic can 
provoke an explosive wave of their appearance both in the world and in Russia, and statistics will change.

The variety of digital educational platforms analyzed by us, created by Russian and foreign organizations, however, cannot meet the identified problems of agricultural business in the field of obtaining additional professional education for their specialists. Therefore, the creation and development of a digital educational platform - the information resource "Open Agrarian University" is relevant and timely.

The creation of a digital educational platform will provide a high technological level for the implementation of a wide range of distance education services intended for specialists working in the agro-industrial complex of Russia and the CIS [26, p. 22]. The digital platform will generate relevant content for both teachers of agricultural universities in Russia, each of whom has extensive experience in implementing additional professional education programs for farmers in their regions, and expert practitioners working at agricultural enterprises. It is assumed that the platform's course database can be integrated with other working educational resources [26, p. 22].

The concept of creating an information resource "Open Agrarian University", developed by the author of this study, can be implemented on a larger scale than an information resource that is present only in the online environment. The "Open Agrarian University" is a kind of agricultural Uber and Yandex at the same time, which brings together an expert and a hungry for knowledge farmer in the educational space, provides prompt answers to problematic industry questions [26, p. 24].

A group of developers representing an industry research institute and an industrial company (the author of this study is a member of the team) has created a digital platform, including the electronic educational resource "Open Agrarian University", version 1.0 of the platform is available at https://agro.university and now offers agribusiness in Russia several practice-oriented courses on agricultural economics and agriculture [26, p. 24].

The organizational scheme of interaction between the subjects of the educational platform - developers of educational content, technical developers, and content consumers, is shown in figure 2 . 


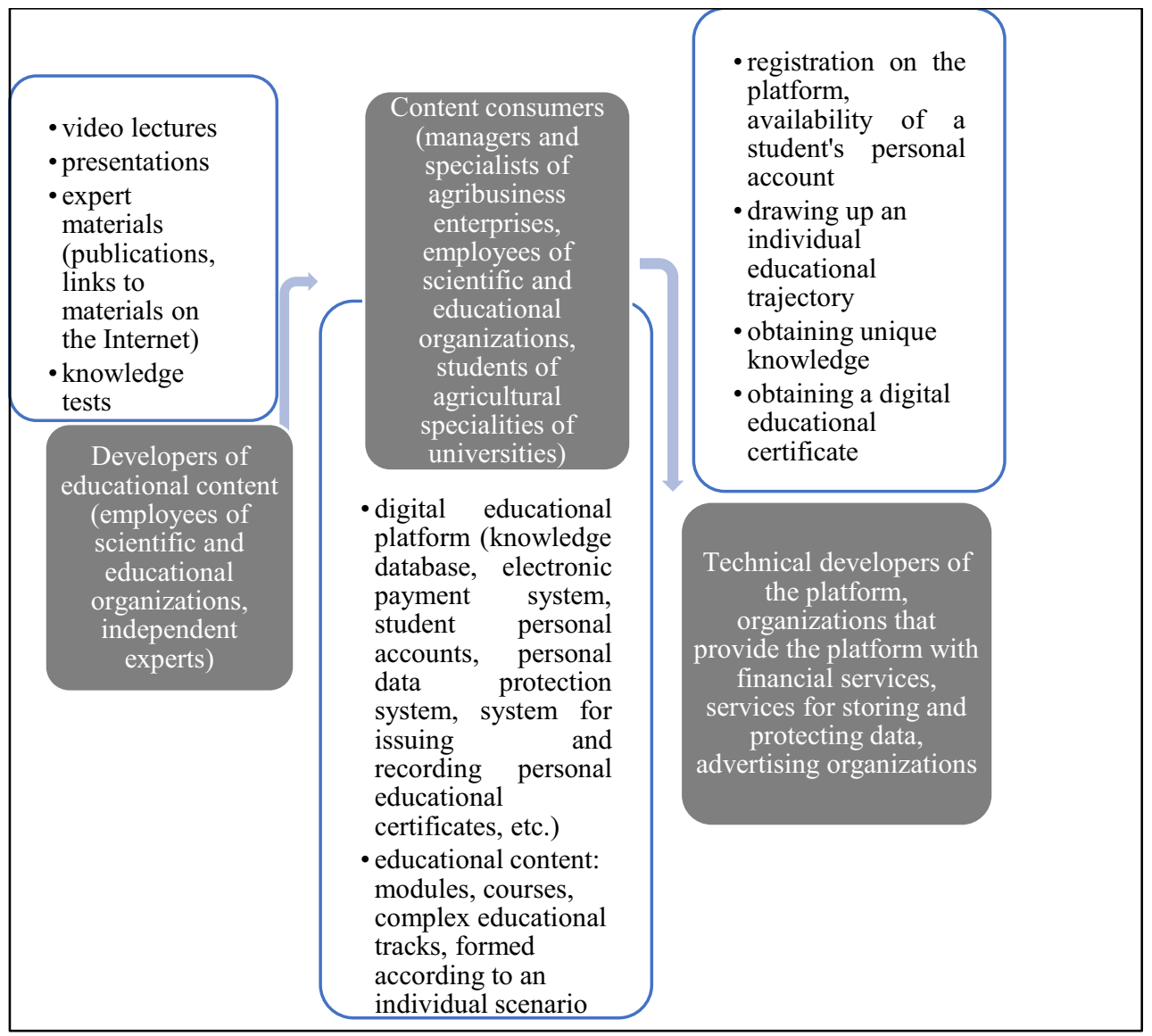

Fig. 2. Organizational scheme of interaction between subjects of the educational platform.

This digital product uses BLOCKCHAIN technology to account for certificates issued to students who have successfully completed their training.

The technical development of the project involves the integration of end-to-end digital technologies of artificial intelligence, virtual and augmented reality for the development and provision of new services through the educational resource; tools and forms of information translation are constantly evolving.

The platform has a number of unique advantages:

1. Key experts of agriculture and agribusiness are on one platform. This makes it possible to provide comprehensive training in various aspects of agribusiness - from methods of regulating the phytosanitary state of the soil to proper preparation for inspections by state regulatory authorities.

2. Only practical and relevant knowledge. This allows to invest the time of agricultural managers in learning only the necessary knowledge, without investing it in research of unnecessary or outdated approaches.

3. Long and short-term modular programs. Two formats of educational courses allow to get a holistic education in agribusiness during the annual course, and to delve into the most relevant point problems by studying a short module.

4. Availability of knowledge 24/7 from the tablet screen. All educational materials, case studies, results of live meetings, materials of practical classes and seminars are available online. This allows to plan own time for training and provides effective time management during the "hot" agricultural seasons. 
5. Personal training plan for each client. Due to the modular structure of the educational process, the client can choose only those courses and sections of knowledge that interest them, without spending time and money on general educational or irrelevant courses.

6. Independent expertise and experience of colleagues. By providing practical group sessions and live meetings with project experts and students in the client fields, it is possible to comprehensively analyze problems and then determine the most effective way to solve problems.

Technical opportunities have been created for students who have registered on the platform (access to registration is open to everyone). For each potential student, a personal account is automatically created, where the selected modules and courses, additional materials in the learning process will be placed; here the student will be tested based on the results of the course, the technical ability to download documents following the training has already been implemented.

\section{Results and discussion}

The positive aspects of the study are:

- system approach and system thinking to create a new information resource " Open agricultural University»;

- implementation of the model of public-private partnership of a large company with state educational institutions;

- in the process of writing the WRC, a pilot project of the information educational resource "Open agricultural University" was actually developed and implemented (version 1.0);

- agreements were signed with leading agricultural universities and research institutes (more than 20 of them).

Additional technical features of the information resource are implemented in the procedures for information protection, protection of personal data of students and teachers who post their courses on the resource.

The development of a set of laws and regulations for the introduction of legally significant electronic interaction between resource subjects was carried out in strict accordance with the decree of the Government of the Russian Federation dated July 6, 2015 No. 676 "On requirements for the procedure for creating, developing, commissioning, operating and decommissioning state information systems and further information storage contained in their databases" [12]. The resolution defines the requirements for the implementation of measures for the creation, development, commissioning, operation and decommissioning of state information systems and further storage of information contained in their databases, carried out by executive authorities acting as public partners and private partners in accordance with public-private partnership agreements in order to increase the effectiveness of the implementation of the powers of executive authorities as a result of the use of information and communication technologies. As key requirements for the digital platform "Open Agrarian University" satisfied the requirements of the protection of information contained in the system requirements for the organization and protection of information contained in the system requirements on the protection of personal data, as the platform provides the availability of such data [28, p. 85].

The company - developer of the technical resource - placed the information resource in the certified data processing center of the Russian company Yandex (Tier 3). We use the most modern methods to ensure data security.

One of the most important directions of creating and developing a digital educational platform for agriculture will be to solve the problem of instant search for relevant 
information for successful agricultural business - the creation of a search service, the socalled AgroYandex. Traditional sources of information that meet these requests now are published reference books, lists, textbooks (printed and electronic versions can be accessed through information systems, posted on the Internet), and websites of organizations [28, $\mathrm{p}$. 85].

In addition, for the first time, an automatic image recognition system based on machine learning will be implemented for instant recognition of pests and diseases of agricultural plants and reference books, arrays of photographic information of specialized organizations. The features of the Yandex.Toloka crowdsourcing platform will be used for adding the required number of object images for recognition for the machine learning system.

\section{Conclusion}

Globally, the expected effect of the full launch of an industry-wide online education platform is to increase the productivity of agribusiness specialists and accelerate management decision-making in the industry.

System approach and system thinking for the formation of a new academic environment, focusing on problems of preparation of specialists, able to implement digital transformation of agriculture in Russia has allowed the development group representing the industry research institute and the industrial company, to create an electronic educational resource the "Open Agrarian University", which contains the unique content created specifically for this educational resource structured by modules and courses.

This is not just a universal system of e-education for students of agricultural universities, but the implementation of the roadmap for digital transformation of the Russian agro-industrial complex in terms of improving additional professional education for agricultural business. The project is based on the principle of continuous development, where the interest of an industrial partner with a deep and broad presence in the market of agricultural products moves the project forward. At the same time, the project leaves an absolute possibility of implementation in the model of public-private partnership - with state educational institutions, state corporations, and industry unions [28, p. 85-86].

The role of the "Open Agrarian University" information resource in the system of additional professional agricultural education will be enhanced by consolidating other information resources and providing additional information services for agribusiness. Thus, the plans for the development of the information resource include integration with the databases "Seed production: seeds of domestic selection", "Electronic map of agricultural land", both at the federal and regional levels. The information resource already presents the best available digital products made in Russia.

\section{Acknowledgment}

The study was carried out within the framework of the grant agreement No. 075-15-20191939 dated December 10, 2019. Unique project identifier RFMEFI60719X0302.

\section{References}

1. M. Petrov, V. Burov, M. Shklyaruk, A. Sharov, Government as a platform, Centre of Strategical Developments

https://www.csr.ru/wpcontent/uploads/2018/05/gosudarstvo-kak- 
2. Forecast of scientific and technological development of the agro-industrial complex of the Russian Federation for the period up to 2030, developed by the NRU "Higher School of Economics", approved at the meeting of the Government Commission on agro-industrial complex and sustainable rural development (2016)

3. Decree of the President of the Russian Federation, On approval of the strategy of scientific and technological development of the Russian Federation, 642 (2016)

4. Decree of the President of the Russian Federation, On measures to implement the state scientific and technical policy in the interests of agricultural development, 350, (2016)

5. Decree of the Government of the Russian Federation, On approval of the federal scientific and technical program for the development of agriculture for 2017-2025, 996 (2017)

6. The program "Digital Economy of the Russian Federation, Order of the Government of the Russian Federation,1632-p (2017)

7. Decree of the President of the Russian Federation, On national goals and strategic objectives of the development of the Russian Federation until 2024, №D04 (2018)

8. TAdviser: government, business, IT, http://www.tadviser.ru/index.php/

9. Passport of the National Program "Digital Economy of the Russian Federation". Minutes of the Presidium of the Presidential Council for strategic development and national projects $\mathbf{1 6}$ (2018)

10. The decree of the Government of the RF dated May 3, 2019 № 551 "About state support of programs of activity of the leading research centers implemented by the Russian organizations for the purpose of ensuring development and implementation of road maps of development of perspective "end-to-end" digital technologies"

11. Research of the online education market in Russia, Barometer of online education (2019) https://drive.google.com/file/d/1t-gafwZlP-eJ3yiabGNR4mtwDznzDNhq/view

12. Government resolution No. 676 dated July 6, 2015, On requirements for the procedure for creating, developing, commissioning, operating and decommissioning state information systems and further information storage contained in their databases

13. S. B. Ognivtsev, International agricultural journal, 2(362), 16-22 (2018)

14. T.N. Astakhova, M.O. Kolbanev, A.A. Shamin, Bulletin of the NSEEU, 6(85), 5-17 (2018)

15. S.G. Salnikov, N.Yu. Tukhina, Bulletin of the Moscow Humanitarian and Economic Institute, 3, 5-10 (2018)

16. T.I. Ashmarina, E.I. Zaltan, Economics of agriculture of Russia, 3, 49-53 (2019)

17. A.E. Shamin, O.A. Frolova, Nikon readings, 23, 328-330 (2018)

18. O.V. Shumakova, T.G. Mozzherina, S.Yu. Komarova, Innovative development, 9(26), 143-146 (2018)

19. I.A. Ganieva, Achievements of science and technology of the agro-industrial complex, 33(12), 110-116 (2019)

20. A. Jasem, S.A. Zolotov, Bulletin of NSEEU, 3(82), 99-107 (2018)

21. A.N. Adukova, Bulletin of the NSEEU, 11(90), 14-23 (2018)

22. T.V. Semenova, K.A. Vilkova, I.A. Shcheglova, The issues of education, 2, 173-97 (2018) DOI: 10.17323/1814-9545-2018-2-173-197.

23. S.M. Evans, C. Ward, S. Reeves, Med Teach, 41(2), 215-222 (2019) doi: 10.1080/0142159X.2018.1460656. 
24. M.G. Erickson, M.A. Erasmus, D.M. Karcher, et al., Poult Sci., 98(12), 6593-6601 (2019) doi: 10.3382/ps/pez491.

25. J.R. MacKay, F. Langford, N. Waran, J Vet Med Educ., 43(3), 287-301 (2016) doi: 10.3138/jvme.0415-054R2.

26. I.A. Ganieva, S.V. Koteev, N.E. Bobrov, Achievements of science and technology of the agro-industrial complex, 34(4), 21-25 (2020) doi: 10.24411/0235-2451-202010404.

27. I.A. Ganieva, Achievements of science and technology of the agro-industrial complex, 33(4), 5-7 (2019) DOI: 10.24411/0235-2451-2019-10401

28. I.A. Ganieva, N.E. Bobrov, Achievements of science and technology of the agroindustrial complex, 33(9), 83-86 (2019) DOI: 10.24411/0235-2451-2019-10918 